\title{
ASSISTEENCIA DE ENFERMAGEM A PACIENTES EM FASE TERMINAL
}

\author{
Aidê Ferreira Ferraz ${ }^{1}$, Daclé Vilma de Carvalho2, Tânia Maria Picardi Faria Costa3 e \\ Wilson Souza Carvalho 4 .
}

FERRAZ, A. F. et alii. Assistência de enfermagem a pacientes em fase terminal - Rev. Bras. Enf., Brasília, 39 (1): 50-60, jan./mar., 1986.

\begin{abstract}
RESUMO. Este trabalho refere-se a um estudo sobre a assistência de enfermagem a pacientes em fase terminal. Foi realizado com profissionais e ocupacionais de enfermagem de hospitais gerais de Belo Horizonte, que atuam junto a este tipo de pacientes. Foram identificadas as necessidades básicas que devem ser atendidas na prestação da assistência ao paciente em fase terminal. Verificou-se também se estes profissionais e ocupacionais sentem alguma dificuldade em assistir a esses pacientes. Foram também levantadas, junto à população, sugestões para sanar ou minimizar as dificuldades sentidas na prestação da assistência ao paciente em fase terminal.
\end{abstract}

ABSTRACT. This work, which refer to a study about nursing care to pacients in the terminal stage, was made in Belo Horizonte with nursing staff of general hospitals, that work with that kind of patients. We identified the basic needs for the care of patients in terminal stage. It was also checked if that staff have any difficulties in talking care of those patients. Together with the population under study we also searched for suggestions to solve or minimize the difficulties found in providing care to patients in termina stage.

O morrer, além de um processo, é um caminhar que significa uma busca, uma objetivação, um atingir. Cabe a cada um viver o morrer, curti-lo como uma etapa, um "desideratum" também, um culminar mais que um terminar.

\section{ASSUMPÇÃO}

\section{INTRODUÇÃO}

A morte é parte integral da existência humana e, no entanto, é um tema evitado e até mesmo negado em nossa sociedade. Isso decorre, dentre outros fatos, o de sermos poupados, desde a infância, de vivenciarmos "a morte" e "o morrer".

Conforme coloca ASSUMPÇÃO3, "a morte" e "o morrer" embora pareçam a mesma coisa, são diferentes. "A morte" significa o final da vida material e "o morrer" é o processo através do qual ocorre a morte.

Em nossa sociedade, "a morte" e "o morrer" constituem um tabu. Em geral, as crianças são afastadas das pessoas que estão morrendo ou já morreram, e de assuntos ligados à morte. Agindo

1 - Enfermeira - Prof essor Auxiliar'II da Escola de Enfermagem da UFMG

2 - Enfermeira - Professor Adjunto II da Escola de Enfermagem da UFMG

3 - Enfermeira - Professor Auxiliar III da Escola de Enfermagem da UFMG

4 - Enfermeiro - Prof essor Auxiliar I da Escola de Enfermagem da UFMG 
dessa forma, pode-se incutir nelas um medo desnecessário (KÜBLER-ROSS10).

Falar sobre a morte causa um mal-estar nas pessoas. Isso ocorre até mesmo com os profissionais que lidam com indivíduos portadores de uma doença, que os levará fatalmente à morte. Quando a equipe de enfermagem defronta-se com o paciente em fase terminal, observa-se uma mudança no comportamento da mesma, refletindo diretamente na qualidade da assistência.

Segundo GHEZZI7, a adaptação e possível aceitação da doença, pelo doente e familiares, dependerão, além de outros fatores, da atitude da equipe multiprofissional frente ao diagnóstico. Assim, é fundamental que o pessoal de enfermagem examine seus sentimentos e dificuldades frente à situação "morte". Deve-se lembrar que nem mesmo os profissionais da saúde aceitam naturalmente a morte. Portanto, torna-se necessário que esse tema seja trabalhado e aceito com naturalidade.

Observa-se que o paciente em fase terminal é quase sempre relegado a segundo plano, por quase que toda a equipe de saúde, em função de pacientes com possibilidades de cura. Os cuidados prestados são basicamente aqueles ligados ao conforto físico, atendimento das necessidades fisiológicas, observação de "TPR e PA", e implementação da terapêutica medicamentosa. GHEZ$\mathrm{ZI}^{7}$ observou também que há uma diminuição da qualidade da assistência de enfermagem ao paciente em fase terminal.

Pela colocação de KÜBLER-ROSS10, freqüentemente os familiares, e mesmo o pessoal médico, consideram que tudo o que o paciente moribundo deseja é sentir-se confortável. Desde que é lavrada a sentenç̧a de morte, a tendência é de se afofar os travesseiros. Naturalmente que prestar os cuidados físicos não está errado. Acontece que se confundem as prioridades. A vida de alguém está terminando e, provavelmente, essa pessoa desejaria dizer, fazer e ouvir coisas importantes antes de morrer. Portanto, é fundamental que se dê ao moribundo a oportunidade de ser ouvido e compreendido. VEIGA ${ }^{14}$ cita também que ouvi-lo e com ele estabelecer metas é tão importante quanto executar os cuidados específicos. Acrescenta, ainda, a importância de proporcionar-lhe oportunidades para demonstrar seus sentimentos e necessidades.

A equipe de enfermagem não enf renta a situação "morte" naturalmente e, por conseguinte, surgem dificuldades em prestar assistência ao paciente em fase terminal. Conforme VEIGA ${ }^{14} \mathrm{e}$ SILVA $^{13}$, o pessoal de Enfermagem sente medo ao pensar que o paciente ou familia façam pergun- tas que não possa responder e, por isso, executa os cuidados apressadamente para que eles não tenham oportunidade de fazê-las. Para KỦBLER-ROSS ${ }^{10}$, o paciente que está à morte não é visto como lima pessoa e, deste modo, não se fala com ele considerando-o como tal.

Uma vez que o indivíduo é um ser biopsicossocial e espiritual, desde o nascimento até a morte, deve ser assim visto e assistido. KÜBLER-ROSS 10 coloca ainda que "o morrer" deveria ser considerado como uma fase do viver e sujeito a crescimento, obrigações e oportunidades como qualquer outra fase da vida.

$\mathrm{O}$ indivíduo em fase terminal é tratado basicamente no que se refere às necessidades psicobiológicas. Segundo $\operatorname{COSTA}^{8}$, existe uma tendência dos enfermeiros em não tratar o paciente numa visão global de suas necessidades, havendo uma ênfase nos cuidados físicos, numa aparente fuga do problema angustiante que é a morte.

Mediante a problemática apresentada, sentiu-se necessidade de se fazer um estudo exploratório junto a profissionais e ocupacionais de enfermagem, com os seguintes objetivos:

- Agrupar, em necessidades humanas básicas, as ações e cuidados de enfermagem considerados importantes pelos profissionais e ocupacionais de enfermagem, para uma ef etiva assistência ao paciente èm fase terminal.

- Verificar se os profissionais e ocupantes de enfermagem sentem alguma dificuldade em assistir o paciente em fase terminal.

- Listar as sugestões apresentadas pelos profissionais e ocupacionais de enfermagem, para sanar ou minimizar as dificuldades sentidas na prestação de assistência de enfermagem ao paciente em fase terminal.

\section{METODOLOGIA}

\section{Local}

O estudo foi realizado em cinco hospitais gerais de Belo Horizonte.

\section{População e Amostra}

A população deste estudo corresponde a todos os profissionais e ocupacionais de enfermagem dos hospitais, campo do estudo, que atuavam em unidades de internação nos três turnos de trabalho e que estavam assistindo, ou haviam assistido, pacientes em fase terminal.

A amostra foi constituída de todos os profissionais e ocupacionais de enfermagem dos três turnos de trabalho que:

- estavam presentes na unidade no dia e hora estipulados para a coleta de dados e se dispuseram a dar entrevista; 
- estavam assistindo, ou haviam assistido, pacientes adultos em fase terminal, pelo menos há oito dias que antecederam a entrevista.

\section{Instrumento para coleta de dados.}

Para a coleta de dados utilizou-se um formulário (ANEXO 1) com itens para caracterizar a amostra e perguntas inerentes aos objetivos do trabalho. Todos os itens foram testados e validados.

\section{Coleta de dados:}

Os dados foram coletados através de entrevista, pelos próprios autores, no primeiro semestre de 1985. Para a coleta de dados, observaram-se os seguintes critérios e seqüência:

19) Solicitou-se autorização para utilizar os hospitais como campo de estudo.

20) Fez-se um levantamento nos hospitais, para identificar as unidades em que existiam internados e considerados em fase terminal pelo pessoal de enfermagem.

30) Fez-se um levantamento dos profissionais e ocupacionais de enfermagem que estavam assistindo pacientes em fase terminal, ou os haviam assistido, pelo menos há oito dias atrás.

40) Solicitou-se a colaboração dos profissionais e ocupacionais que estavam presentes na unidade, na data e hora estipuladas para a entrevista, tendo sido entrevistados todos aqueles que se dispuseram a colaborar com o trabalho.

\section{Análise dos dados:}

Após a coleta de dados, estes foram tabulados e analisados estatisticamente, através de percentagem e média.

- As ações e cuidados de enfermagem foram classificados em necessidades humanas básicas, segundo HORTA $^{9}$, nos níveis: Psicobiológico, Psicossocial e Psicoespiritual.

- As dificuldades sentidas e as sugestões dadas pelos profissionais e ocupacionais. foram agrupadas a partir das respostas obtidas na entrevista.

\section{RESULTADOS E DISCUSSÃO}

De acordo com os critérios estipulados, a amostragem foi constituída de 125 elementos. Porém, como uma entrevista não foi concluída devido a intercorrência na unidade, a amostra foi constituída de 124 entrevistados, sendo 19 $(13,3 \%)$ do sexo masculino e $105(84,7 \%)$ do sexo feminino. Quanto à categoria profissional, 28 $(22,6 \%)$ são enfermeiros, $59(47,6 \%)$ auxiliares de enfermagem e $37(29,8 \%)$ atendentes.
Foram agrupados na categoria auxiliar de enfermagem, 5(cinco) técnicos que tinham essa formação mas que estavam atuando como auxiliar de enfermagem.

Quanto à faixa etária, as maiores percentagens $42,0 \%$ e $40,3 \%$, situam-se na faixa etária de 18 a 30 anos e 31 a 42 anos, respectivamente. Não houve nenhum entrevistado na faixa etária correspondente a 60 anos ou mais.

Em relação à religião, a maior percentagem (75,0\%) concentra-se na religião católica. A seguir, vem o grupo evangélico com 14,6\%.

A maior concentração de respondentes, quanto ao tempo de exercício profissional, situa-se no grupo de 6 (seis) anos e mais. Nesse, o tempo máximo foi de 27 anos.

Quanto ao turno de trabalho, 106(85,5\%) dos respondentes atuam no turno diurno e $18(14,5 \%)$, no noturno.

Praticamente todos os entrevistados tinham experiência anterior em assistir pacientes em fase terminal, com exceção de $3(2,4 \%)$.

\section{Ações e Cuidados Citados}

Dos 731 ações e cuidados mencionados pelos entrevistados, 476 (65,1\%) foram agrupados em necessidades básicas dos três níveis, apresentadas no Quadro I. Dos demais itens, 245 (33,5\%) não puderam ser englobados em necessidades básicas, constituindo, porém, itens importantes para uma adequada assistência, como pode ser observado no Quadro II, e 10 (1,4\%) foram abandonados por não se enquadrarem na questão proposta.

Dos 476 cuidados e ações de enfermagem que os respondentes mencionaram como sendo importantes para uma ef etiva assistência ao paciente em fase terminal, $281(59,0 \%)$ referiam-se às necessidades psicobiológicas, $153(32,1 \%)$ às necessidades psicossociais e $42(8,8 \%)$, às necessidades psicoespirituais.

As necessidades foram identificadas a partir das ações e cuidados citados que foram considerados como indicativos de necessidades básicas. Ao se identificar uma necessidade através das ações ou cuidados não significa que esses tenham sido mencionados pela maioria dos respondentes e foram considerados mesmo aqueles mencionados por apenas um entrevistado.

As necessidades básicas foram dispostas no Quadro I em ordem decrescente quanto à frequiência com que foram mencionados as ações e cuidados. 
QUADRO I

RELAÇÃO DAS NECESSIDADES HUMANAS BÁSICAS AGRUPADAS NOS TRÊS NÍVEIS, IDENTIFICADAS A PARTIR DAS AÇÕES E CUIDADOS CITADOS

\section{NECESSIDADES HUMANAS BĀSICAS}

\begin{tabular}{|c|c|c|}
\hline Psicobiológicas & Psi cossociais & sicoespirituai \\
\hline Cuidado corporal & Comunicacão & \\
\hline Conforto físico & $\begin{array}{l}\text { Comunicaçao } \\
\text { Segurança emo- }\end{array}$ & $\begin{array}{l}\text { Segurança } \\
\text { espiritual }\end{array}$ \\
\hline Terapêutica medi- & cional & \\
\hline camentosa & Gregária: & \\
\hline Nutrição & - presença de & \\
\hline Motilidade & enfermeira & \\
\hline $\begin{array}{l}\text { Equilíbrio respi- } \\
\text { ratório }\end{array}$ & $\begin{array}{l}\text { - presença de } \\
\text { familiares }\end{array}$ & \\
\hline Equil1brio térmico & - com outros & \\
\hline Equilíbrio cárdio- & pacientes & \\
\hline -circulatório & - com quem ama & \\
\hline Percepção dolorosa & Ambiente & \\
\hline Integridade cutâneo- & Recreação & \\
\hline- mucosa & Privacidade & \\
\hline Oxigenação & & \\
\hline $\begin{array}{l}\text { Equilíbrio respi- } \\
\text { ratório }\end{array}$ & & \\
\hline $\begin{array}{l}\text { Equil íbrio cárdio- } \\
\text {-respiratório }\end{array}$ & & \\
\hline Hidratação & & \\
\hline Orientação tempo- & & \\
\hline - espaço & & \\
\hline Segurança física & & \\
\hline $\begin{array}{l}\text { Eliminação intes- } \\
\text { tinal }\end{array}$ & & \\
\hline Eliminação vesical & & \\
\hline
\end{tabular}

\section{Necessidudes Psicobiológicas}

Comparando-se as necessidades psicobiológicas identificadas com aquelas prescritas na literatura consultada, observa-se uma coerência no que se refere às necessidades psicobiológicas do paciente em fase terminal, que devem ser atendidas.

Deve-se salientar que as ações e cuidados agrupados em necessidades que concentraram maior número de respostas, cuidado corporal, foram mencionadas de maneira específica, por $63(50,8 \%)$ dos entrevistados. Esta percentagem poderá ser acrescida de $30,5 \%$, se for considerado que 38 dos profissionais e ocupacionais não citaram, especificamente, ações e cuidados inerentes às necessidades, mas referiram-se genericamente a "cuidados básicos" "cuidado integral" e "cuidado individualizado". Nesses cuidados, supõe-se estejam implícitos os cuidados relativos às neces- sidades psicobiológicas, resultando assim, um total de $101(81,4 \%)$ para cuidado corporal.

As demais necessidades desse nível não atingem o percentual de $50,0 \%$ quando analisadas as citações específicas. No entanto, observar-se-á um acréscimo do mesmo percentual ao se proceder o raciocínio acima.

Considera-se relevante o fato de terem sido identificadas as necessidades desse nível, também mencionadas na literatura específica.

\section{Necessidades Psicosso ciais}

As ações e cuidados (153) da área psicossocial foram agrupados em necessidades que estão apresentadas no Quadro I. A necessidade de comunicação representa o maior percentual $(32,0 \%)$. Tanto a comunicação verbal quanto a não-verbal são essenciais para o relacionamento humano. Segundo BELAND \& $\operatorname{PASSOS}^{4}$, a comunicação verbal auxilia mais o paciente nas primeiras fases do processo "do morrer" descritas por "KUBLER-ROSS 10 , pois proporciona ao paciente a oportunidade de conhecer a realidade da situação, obtendo respostas para suas dúvidas e externando seus sentimentos. A comunicação não-verbal torna-se mais eficaz no estágio de resignação. São atitudes terapêuticas, nesta fase, o tocar o paciente, sentar-se perto dele e demonstrar interesse por ele e por seus problemas.

Embora se saiba que o contato físico é uma forma de comunicação não-verbal, não foi englobado no item comunicação (QUADRO I), por ser uma necessidade humana básica específica e também para enfatizar a importância a ele dada por alguns entrevistados que fizeram citações como. "alguns pacientes sentem que vão morrer e a estes me dedico inteiramente. Fico ao lado dele para que sinta a minha presença... segurar na mão do paciente fala mais do que as palavras". Esta colocação é reforçada na literatura específica, pois segundo FUERST et alii6, o tato é mais expressivo para transmitir a intenção de atitudes e sentimentos do que a comunicação verbal e outras formas de comunicação não-verbais.

As ações e cuidados que levaram à identificação da necessidade gregária foram basicamente: "presença do enfermeiro ao lado do paciente", "presença de familiares", "presença das pessoas que ama", "não isolar o paciente dos demais", "permitir a permanência de familiares junto ao paciente" e "não deixar o paciente sentir-se sozinho".

Considera-se que quando o paciente está hospitalizado e é portador de uma doença terminal, deixa de viver o seu status (Grupo familiar, de trabalho e de lazer) e a necessidade gregária estará, então. afetada. Cabe ao pessoal de enfer- 
magem, identificar essa necessidade e procurar de alguma forma minimizar, no paciente, a sensação de "estar só". As citações acima especificadas podem ser consideradas como formas de atendimento a essa necessidade, já que a própria hospitalização e condição do paciente limitam a sua participação em grupos sociais. Entretanto, ao se atender a necessidade gregária, deve-se ter o cuidado de garantir ao paciente um ambiente tranqüilo e com uma certa privacidade que foram também citados pelos entrevistados (QUADRO I).

Muitos pacientes, considerados em fase final, podem permanecer lúcidos até o último momento de sua vida. Nem todos podem contar permanentemente com alguém da família ao seu lado. Passam horas inertes no leito, olhando para o teto e mergulhados na sua dor e em seus pensamentos. Deve-se proporcionar a estes pacientes algum tipo de recreação dentro das condições e preferências de cada um.

Folhear revistas, ouvir música suave, ouvir uma leitura agradável e assistir televisão são alguns meios que podem ser utilizados na tentativa de minimizar o seu sof rimento e, conseqüentemente, proporcionar momentos de tranqüilidade.

As ações e cuidados citados, que foram agrupados em segurança emocional, representam $28,1 \%$ das citações do nível psicossocial. Uma das características das necessidades humanas básicas é o inter-relacionamento delas. Algumas são mais interdependentes do que outras, porém, a segurança emocional está ligada a todas as outras necessidades. Considerando que é praticamente impossível estar em equilíbrio com todas as necessidades, pode-se dizer, que também será impossível conseguir plena segurança emocional.

Supondo-se que o paciente em fase terminal tenha afetadas quase todas as suas necessidades e que seja característica deste paciente ser mais inseguro e instável emocionalmente do que outros, torna-se necessário que todas as ações de enfermagem estejam voltadas para o atendimento dessas necessidades.

Orientar o paciente sobre cuidados $\mathrm{e}^{-}$tratamentos; estar perto dele; procurar elevar sua auto-estima e auto-conceito, dar-lhe oportunidade para que expresse seus medos e ansiedade, responder objetivamente seus questionamentos e atendê-lo prontamente são exemplos de procedimentos que poderão minimizar a ansiedade do paciente e, quando não observados, poderão constituir a "gota d água" para um maior desequilíbrio emocional.

\section{Necessidade Psicoespiritual}

Das 124 entrevistas. obtiveram-se 42 menções de ações e cuidados inerentes à assistência espiri- tual sendo que $17(40,0 \%)$ dessas, foram feitas por enfermeiros.

Praticar sua religião é para o indivíduo, em qualquer circunstância, não só uma necessidade como também um direito. De modo geral, quando as pessoas ficam doentes, elas se voltam para a religião numa busca de apoio e conforto (BELLAND \& PASSOS $)^{4}$. Esse apoio e conforto pode ser mais adequadamente proporcionado por lideres religiosos. Esses deveriam ser considerados membros integrantes da equipe que assiste o paciente em fase terminal (FUERST et alii) 6 . Isso, sem dúvida nenhuma, ajudaria o paciente no atendimento de sua necessidade espiritual, tendo observadas as especificidades inerentes à sua religião. Essa participação seria muito útil pois, por mais que os elementos da equipe que assistem o paciente estivessem voltados para o atendimento desta necesidade, estariam sujeitos a defrontar-se com práticas religiosas por eles desconhecidas e/ou incompatíveis com sua crença e princípios religiosos, que também devem ser respeitados.

Mesmo com a participação dos líderes religiosos na assistência espiritual ao paciente, não se exclui a responsabilidade do pessoal de enfermagem em identificar e procurar atender, de alguma forma, esta necessidade. Ao fazê-lo, o enfermeiro deve ter sempre em mente que a prestação da assistência espiritual deve ser feita segundo as peculiaridades da crença e os desejos do paciente. Porém, se não se sentir apto, ou defrontar-se com situações em que as práticas religiosas do paciente forem contra seus princípios, deverá providenciar que outra pessoa o faça.

É necessário atentar para certas práticas religiosas que podem interferir, não só no tratamento como nas próprias condições do paciente. Em casos de exigência do paciente em realizar práticas dessa natureza, o pessoal de enfermagem deve orientá-lo sobre as implicações das mesmas e que deve assumir a responsabilidade de sua decisão.

"Se o paciente tem uma religião, uma crença, ele deve ser respeitado e ajudado a sentir-se seguro nela. Não se deve tentar mudar sua fé na última hora". Mediante esta colocação feita por uma auxiliar de enfermagem entrevistada, há que se questionar a interferência de pessoas de outros credos, que não o do paciente, nos momentos finais de sua vida. 
Ações e Cuidados que nāo Puderam ser Agrupados em Necessidades Básicas.

- As ações e cuidados hão relacionados com Necessidades Humanas Básicas, mas que foram consideradas importantes para uma adequada assistência, estão apresentados no quadro a seguir.

QUADRO II - AÇÕES E CUIDADOS DE ENFERMAGEM ESSENCIAIS PARA UMA EFETIVA ASSISTENCIA DE ENFERMAGEM NÃO AGRUPADOS EM NECESSIDADES BÁSICAS.

\section{AÇÕES E CUIDADOS}

Prestar cuidado integral

Prestar assistência individualizada

Prestar cuidados básicos

Prestar cuidados pedidos

Observar o paciente

Dar cuidados mais freqüentes

Atender prontamente

Dar prioridade ao paciente em relação a outros

Compreender reações do paciente

Prestar assistência mais humana

Proporcionar alívio do sof rimento

Não deixar o paciente sentir-se abandonado

Tratar o paciente com delicadeza, como se fosse da família

Demonstrar respeito

Demonstrar dedicação, atenção, carinho e amor

Transmitir confiança, segurança e força

Liberar visitas

Não perder a paciência com o paciente e a famılia

Ter controle emocional

Preparar o paciente para a morte

Assistir à família

Manter entrosamento entre a equipe de enfermagem e médica

Identificar problema que gostaria de resolver e providenciar solução junto a amigos e familiares

Os ítens "cuidado integral" e "cuidado individualizado" foram mencionados com maior freqüência $(16,1 \%)$ pelos entrevistados e, quando analisados quanto à categoria profissional, foram citados por $50,0 \%$ dos enfermeiros. Esse fato demonstra que ainda não há uma grande preocupação dos elementos da equipe de enfermagem em se prestar assistência ao indivíduo como um todo.
Segundo EPSTEIN5, as necessidades do homem devem ser respeitadas e valorizadas como o indivíduo as vê, dentro de sua problemática existencial. Daí a importância da assistência individualizada.

Desde o nascimento até a morte, o indivíduo possui as necessidades em todos os níveis e, mesmo estando em fase final, ele é um todo indivisível. Portanto, torna-se imprescindível que se considere, na prestação da assistência, o conceito holístico do homem. $\mathrm{O}$ cuidado integral $\mathrm{e}$ individualizado deve ser o objetivo de todo enfermeiro na assistência ao indivíduo em qualquer fase da vida.

Foi citado, ainda, que é importante "prestar cuidados pedidos". Sem dúvida nenhuma, dentro do possível, isso deve ser atendido. Porém, a solicitação do paciente deve ser satisfeita na medida em que ela não venha prejudicar o seu tratamento. Sempre que possível, o plano de cuidados deve ser estabelecido junto com o paciente. Participando deste, ele sentirá que tem ainda algum poder decisório sob si próprio, estimulando assim, o seu auto-conceito. A participação do paciente na elaboração de seu plano de cuidados fará com que este fique mais adequado com suas necessidades e desejos. Assim, os cuidados e tratamentos propostos terão maior aceitação e cooperação por parte do paciente.

Compete à enfermagem uma "observação constante" do paciente a fim de captar manifestações de necessidades, uma vez que o paciente em fase terminal, além de apresentar alterações emocionais, pode estar também com a capacidade sensorial diminuída, dificultando a percepção de suas próprias necessidades. $\mathrm{O}$ paciente em fase terminal pode, a qualquer momento, apresentar no seu quadro clínico alterações que exijam um atendimento de emergência. Atendê-lo prontamente e primá-lo em relação aos demais pacientes são atitudes essenciais para evitar um aumento do estresse ou conseqüências irreversíveis.

De modo geral, os pacientes portadores de uma doença terminal são instáveis emocionalmente. Segundo KƯBLER-ROSS10, estes podem apresentar comportamentos caracterizados em fases de Negação, Raiva, Negociação, Depressão e Aceitação. Portanto, o comportamento do paciente sofrerá alterações de acordo com a fase em que ele estiver. É necessário que o enf ermeiro a identifique e compreenda as reações do paciente.

Segundo o relato de uma das auxiliares de enfermagem entrevistadas, "o profissional tem que 
ser sensível para perceber as diferenças de comportamento e reações do paciente e dar atenção devida a cada caso."

Quando o paciente está em fase de revolta, muitas vezes, suas reações são de agressividade. Ele a descarrega sobre o pessoal de enfermagem, médico, família e amigos. Critica tudo e todos. Segundo BELAND \& PASSOS ${ }^{4}$, se as pessoas estiverem alertas para o princípio de que hostilidade gera hostilidade, é mais provável que consigam um melhor nível de relacionamento. $\mathrm{O}$ paciente perceberá que se está fazendo esforço para compreender seus sentimentos e que os que tratam dele preocupam-se com sua pessoa. Assim, sentir-se-á aceito apesar de seu comportamento.

Os sentimentos de desemparo, abandono, desesperança, desespero, tristeza e solidão são vividos muitas vezes pelos pacientes (ASSUMPÇÃO ${ }^{3}$, BELAND \& PASSOS ${ }^{4}$ ). Estes se tornam mais sensíveis a tudo, são emotivos, frágeis, carentes e sentem-se desamparados. Portanto, exigem e merecem da enfermagem maior dedicação, compreensão, atenção e, acima de tudo, respeito ao seu sofrimento, como mencionado pelos entrevistados.

O paciente hospitalizado sof re um afastamento de suas atividades, de seus amigos e de sua família. $\mathrm{O}$ ambiente e as normas hospitalares a que fica submetido, como, por exemplo, o horário de visitas, contribui para que o paciente tenha aumentado seu sentimento de abandono e solidão pois, somente nos dias e horas estabelecidos, poderá ter junto a si aquelas pessoas que lhe são queridas. É necessário que a equipe de enfermagem esteja sensibilizada para perceber, esses sentimentos e que seja flexível no sentido de promover e facilitar a visita de familiares e amigos, de acordo com as condições do paciente, que certamente se sentirá emocionalmente mais seguro.

Para BELAND \& PASSOS4, estar com alguém é desejo comum a todos os indivíduos inclusive àqueles que apresentam alguma limitação. Inclui-se aqui o paciente em fase terminal. Segundo GHEZZI 7 , é necessário transmitir ao paciente mensagem de fé, não abafar a esperança e assegurar-lhe que não está só. De acordo com uma atendente de enfermagem entrevistada, "deve-se atender o paciente sempre que necessitar, e estar próximo dele para lhe dar segurança e ajudá-lo a suportar com resignação e firmeza, os momentos pelos quais está passando". Outra entrevistada afirmou que "a enfermagem torna-se o único apoio do paciente", pois há casos em que a familia supera, segundo
PIMENTEL et alii12, a fase do luto antes que a morte aconteça de fato.

O controle emocional não corresponde a uma ação ou cuidado, mas deve ser uma característica do enfermeiro. Ter esse controle não pressupõe a ausência de envolvimento emocional, pois ele é necessário para a prestação de uma adequada assistência, desde que mantido em nível terapêutico.

Dois entrevistados mencionaram que deve-se enganar o paciente sobre sua situação. É comum que os profissionais de saúde comportem-se deste modo. Pode ser que isso aconteça com a intenção de proteger o doente, ou como uma forma dos elementos da equipe de saúde protegerem a si próprios de perguntas para as quais não têm respostas. Segundo ASSUMPÇÃO ${ }^{2}$, os profissionais de saúde não conversam abertamente com o doente em fase terminal sobre sua condição, basicamente por desconhecimento, pela maioria deles, da realidade psicológica do paciente e por não terem ainda solucionado os seus próprios problemas relacionados à morte.

Preparar-se para a morte deve ser visto como um direito do homem. No entanto, o tema morte só deve ser discutido com o paciente quando se conhecer a sua maneira de reagir, para proporcionar-lhe o suporte emocional necessário.

A familia do paciente em fase terminal vive também uma situação de crise e está sujeita a vivenciar as mesmas fases descritas por KUBLERROSS10, já citadas. Portanto, o enfermeiro tem a responsabilidade de assistir também a família do paciente (BELAND \& PASSOS 4 ).

$\mathrm{O}$ que se fala com o paciente deve refletir seriedade profissional. Deve haver coerência entre as opiniões emitidas e as condutas de todos os elementos da equipe de saúde (MONTESANO11). Isso só será conseguido se houver uma entrosagem entre todos os membros da equipe que assistem o paciente.

\section{Dificuldades sentidas pelos entrevistaios}

Em relação ao item "dificuldades sentidas", dos 81 que as citaram, foram obtidas 214 menções, perfazendo uma média de 2,6 citações por respondente. Essas foram agrupadas segundo sua procedencia, de forma a facilitar a análise (QUADRO III). 


\begin{tabular}{|c|c|}
\hline $\begin{array}{l}\text { PROCEDÊNCIA DE } \\
\text { DIFICULDADE }\end{array}$ & DIFICULDADES SENTIDAS E ALGUMAS DE SUAS CAUSAS \\
\hline Pessoa que assiste o paciente & $\begin{array}{l}\text { Porque não aceita a morte } \\
\text { Em enf rentar a morte } \\
\text { Porque se sente impotente diante do paciente em fase terminal } \\
\text { Porque se imagina morrendo no lugar do paciente } \\
\text { Porque sente mal-estar } \\
\text { Porque transmite seus medos, angústias, depressão e ansiedade ao } \\
\text { paciente } \\
\text { Em comunicar-se com o paciente } \\
\text { Porque se envolve emocionalmente } \\
\text { Em prestar assistência espiritual } \\
\text { Ser sensível a droga quimioterápica } \\
\text { Em identificar as necessidades do paciente } \\
\text { Porque fica em dúvida se vale a pena prestar cuidado ao paciente em } \\
\text { fase terminal } \\
\text { Ter que deixar o paciente em segundo plano em favor de outro com } \\
\text { possibilidade de cura } \\
\text { Porque fica em dúvida quanto à validade da ressuscitação }\end{array}$ \\
\hline Paciente & $\begin{array}{l}\text { Porque estes pacientes têm maior grau de dependência da enfermagem } \\
\text { Porque estes pacientes sobrecarregam a enfermagem } \\
\text { Devido à mobilização do paciente pesado } \\
\text { Em utilizar da via oral em pacientes com dificuldades de deglutição }\end{array}$ \\
\hline Familiares do Paciente & $\begin{array}{l}\text { Devido ao comportamento dos familiares } \\
\text { Devido à familia sobrecarregar a enfermagem com seus problemas } \\
\text { Em comunicar-se com a família do paciente }\end{array}$ \\
\hline Recursos Humanos e Materiais & $\begin{array}{l}\text { Porque falta pessoal } \\
\text { Porque falta material }\end{array}$ \\
\hline Equipe de Enfermagem & $\begin{array}{l}\text { Comunicação deficiente entre funcionários } \\
\text { Falta de colaboração dos colegas } \\
\text { Falta de continuidade da assistência }\end{array}$ \\
\hline Assistência Médica & $\begin{array}{l}\text { Devido ao comportamento de médicos que interferem na assistência } \\
\text { de enfermagem }\end{array}$ \\
\hline $\begin{array}{l}\text { Formação e experiência } \\
\text { profissional }\end{array}$ & $\begin{array}{l}\text { Pessoal inexperiente em assistir o paciente em fase terminal } \\
\text { Em executar a técnica }\end{array}$ \\
\hline
\end{tabular}

Utilizando os dados do quadro acima, pode-se afirmar que os profissionais têm dificuldades decorrentes de sua própria pessoa e da familia do paciente. Acredita-se, pela análise dos dados que possibilitaram os agrupamentos do Quadro III, que a causa básica dessas dificuldades é a não aceitação da morte. Essas surgem porque na nossa sociedade somos ensinados, desde a infância, a ignorar e até mesmo a negar a morte. Isso faz com que sempre que surge a necessidade de enfrentá-la venham à tona, sob diferentes formas de comportamento, as questões não resolvidas em relação à morte. Ocorre, também, o sentimento de culpa e de fracasso nas pessoas que assistem o paciente e nos familiares deste, quando deparam com a morte do paciente.

Pode-se observar que, na família, esse despreparo é refletido por atitudes desesperadas e por exigências, às vezes descabidas, de múltiplas tentativas para salvar o indivíduo a qualquer preço. Esse tipo de comportamento dos familiares, 
muitas vezes, representa um problema para a equipe de enfermagem, tanto que o mesmo foi citado como uma dificuldade sentida.

Para alguns entrevistados, o envolvimento emocional representa uma dificuldade para assistir o paciente. Isso pode ter origem no fato de que o envolvimento emocional, indevidamente aplicado, pode deixar de constituir um aspecto importante do relacionamento terapêutico.

Outras dificuldades citadas como, "imaginarse morrendo no lugar do paciente" e "transmitir seus medos, angústias, depressão e ansiedade ao paciente", reforçam a idéia de que o envolvimento emocional não ocorre em níveis terapêuticos.

Nos dizeres de um entrevistado "a gente morre um pouco com cada paciente". Parece que a pessoa que assiste o paciente absorve as angústias e problemas do mesmo e vivencia as experiências do seu morrer como se fosse o seu próprio morrer, para o que também não está preparado. Conseqüentemente, é possível que a pessoa que assiste o paciente fique deprimida e sinta-se "incomodada", "chateada", "abalada" e "aflita", englobados no item "mal-estar". Esses sentimentos ocorrem no profissional, não só pela iminência da morte do paciente com quem está emocionalmente envolvido, mas possivelmente, também, pela evidência da própria mortalidade espelhada no outro.

Além das dificuldades já comentadas, pode-se verificar no Quadro II, que a pessoa que assiste o paciente sente outras dificuldades.

Pelas suas próprias características, o paciente em fase terminal apresenta maior grau de dependência. Isso representa uma dificuldade para a assistência, principalmente quando se tem número reduzido de pessoal e/ou falta de material, como foi mencionado pelos entrevistados, havendo conseqüente sobrecarga emocional e de serviço para a equipe de enfermagem. De acordo com a citação de alguns entrevistados, nesse caso, a assistência fica prejudicada, pois muitas vezes o pessoal de enfermagem, por não ter tempo disponível, se vê forçado a deixar o paciente em fase terminal em segundo plano, em favor dos outros com possibilidade de cura.

Considera-se de grande importância para a assistência ao paciente em fase terminal, que todos os profissionais nela envolvidos atuem como uma equipe suficientemente entrosada e que estejam comprometidos com a assistência a fim de garantir a continuidade e a qualidade da mesma.

Levando-se em conta a complexidade e a es- pecificidade da situação vivida pelo paciente em fase terminal, é de se supor que as pessoas com mais experiência de vida e profissional sejam as mais indicadas para assistir a esses pacientes. Imagina-se que tais profissionais encontram mais facilidade em perceber e atender as necessidades do paciente, podendo, portanto, ser-lhes mais úteis naqueles momentos cruciais de sua existência. Observou-se, entretanto, que isso não tem sido considerado por alguns enfermeiros, que têm designado pessoas com até três meses de atividade profissional, para assistir a estes pacientes. Isso foi detectado na coleta de dados, no item referente ao tempo de exercício profissional.

\section{Sugestōes apresentadas pelos entrevistados}

Dos 81 entrevistados que mencionaram dificuldades, foram obtidas 113 sugestões para minimizá-las.

$\mathrm{Na}$ tabulação dos dados observou-se que não havia uma correspondência entre algumas sugestões e as dificuldades sentidas pelo mesmo respondente. Apesar disso, as sugestões foram aproveitadas, pois considerou-se que havia uma dificuldade implícita em cada uma delas.

Para melhor visualização e facilitar a análise, as sugestões foram agrupadas segundo os responsáveis pela viablização das mesmas, como pode ser visto a seguir.

SUGESTÕES APRESENTADAS PELOS PROFISSIONAIS E OCUPACIONAIS PARA MINIMIZAR AS DIFICULDADES SENTIDAS NA PRESTAÇÃO DA ASSISTÊNCIA.

\footnotetext{
I - Sugestōes para a própria pessoa que assiste o paciente

1 - Em relação a si próprio:

- Procurar aceitar a morte

- Preparar-se espiritualmente

- Estudar sobre a assistência ao paciente em fase terminal

- Preparar-se para se comunicar adequadamente com o paciente

- Evitar que os sentimentos interfiram na assistência

- Não apavorar

- Ter interesse pessoal

- Controlar a emoção

- Evitar dar assistência sem estar preparado

2 - Em relação ao paciente e familiares:

- Preparar o paciente para aceitar a morte
} 
- Transmitir fé, carga positiva, confiança

- Fazer histórico detalhado do paciente

- Entender os familiares

- Orientar a família

\section{II - Sugestöes para Escolas de Enfermagem}

- Promover cursos sobre assistência ao paciente em fase terminal

- Promover discussões sobre o tema

III - Sugestões para instituições e serviços de saúde

1 - Em relação à administração da unidade:

- Designar pessoal de enfermagem mais experiente para assistir estes pacientes

- Aumentar recursos materiais

- Organizar a unidade em função do paciente

- Promover melhores condições de trabalho para o funcionário

2 - Em relação a Recursos Humanos:

- Aumentar o quadro de pessoal

- Promover reciclagem para os funcionários

- Orientar pessoal de portaria para atender familiares

- Proporcionar ao funcionário acompanhamento de psicólogo ou pessoa preparada

3 - Em relação ao Paciente:

- Oferecer suporte interprofissional para assistência ao paciente

- Manter as mesmas pessoas cuidando do paciente desde sua admissão

4 - Em relação à Assistência Mé dica:

- Maior atenção médica

- Colocar médicos mais experientes para assistir estes pacientes

5 - Em relação à Equipe de Saúde:

- Ter harmonia nas decisões

Quanto à viabilização das sugestões, vê-se que $31(27,4 \%)$ são da competência da própria pessoa que assiste o paciente. Estas sugestões foram agrupadas em itens referentes à própria pessoa que assiste o paciente e a pacientes e familiares.

Quanto à própria pessoa, as sugestões estão ligadas às dificuldades de não aceitar a morte, em cuidar do paciente. "Conhecer o paciente, prepará-lo para aceitar a morte e prestar assistên-
| cia que abranja os familiares através da compreensão e orientação dos mesmos" são sugestões que referem basicamente às dificuldades mencionadas ligadas ao comportamento do paciente e familiares.

Quanto às dificuldades ligadas à assistência ao paciente e a profissionais inexperientes, foram feitas sugestões cuja viabilização compete às escolas de enfermagem, promovendo cursos e discussões sobre o tema para estudantes e profissionais de enfermagem.

Das 113 sugestões, o maior índice (59,3\%) das menções compete às instituições e serviços de saúde implementá-las. As sugestões estão ligadas às dificuldades encontradas na administração da unidade, recursos humanos, pacientes, assistência medica e equipe de saúde. Estas sugestões referem-se basicamente aos seguintes problemas: pessoal inexperiente designado para cuidar de pacientes em fase terminal; falta de material e pessoal; precárias condições de trabalho; envolvimento emocional; sobrecarga de trabalho; falta de continuidade da assistência; problemas ligados à equipe de saúde e à assistência médica.

\section{CONCLUSÃO}

Dentro das limitações do estudo, conseguiramse identificar 18 necessidades psicobiológicas, 07 psicossociais e a necessidade de segurança espiritual. Foram listados ainda 23 ações e cuidados ou atitudes profissionais, que são também importantes para a prestação de uma assistência efetiva e humana ao paciente em fase terminal.

Tanto os profissionais quanto os ocupacionais de enfermagem, $(65,3 \%)$ sentem alguma dificuldade na prestação de assistência de enfermagem ao paciente em fase final. Foram citados 30 tipos de dificuldades sendo que $50,0 \%$ destas estão ligadas à própria pessoa que assiste o paciente. As demais estão ligadas ao paciente, sua familia, recursos humanos e materiais equipe de enfermagem, assistência médica e experiência profissional.

Em relação às sugestões dos profissionais $\mathrm{e}$ ocupacionais de enfermagem para sanar ou minimizar suas dificuldades, em assistir o paciente em fase final, foram feitas 31 citações. A viabilização de 14 destas $(45,2 \%)$ compete à própria pessoa que assiste o paciente, e a das demais compete às escolas, instituições e serviços de saúde.

Finalizando, transcrevemos a "Declaração dos Direitos da Pessoa Moribunda". 


\section{DECLARAÇÃo DE DIREITOS DA PESSOA MORIBUNDA}

Eu tenho o direito de ser tratado como um ser humano até a minha morte.

Eu tenho o direito de conservar o sentimento de esperança seja qual for a variação em sua focalização.

Eu tenho o direito de ser cuidado por aqueles que podem manter um sentimento de esperança, seja qual for a mudança que possa ocorrer.

Eu tenho o direito de exprimir os meus sentimentos e emoçõès a respeito de minha morte próxima, à minha maneira.

Eu tenho o direito de não ser enganado.

Eu tenho o direito de ser ajudado, assim como a minha família, a aceitar a morte.

Eu tenho o direito de morrer em paz e com dignidade.

Eu tenho o direito de manter a minha personalidade e não ser julgado por minhas decisões que podem ser contrárias às crenças dos outros.

Eu tenho o direito de participar das decisões sobre a minha assistência.

Eu tenho o direito de exigir a continuada assistência médica e de enfermagem, mesmo embora as metas de "cura" possam ser mudadas pelas metas de "conforto".

Eu tenho o direito de não morrer sozinho.

Eu tenho o direito de ser libertado da dor.

Eu tenho o direito de ter as minhas perguntas respondidas honestamente.

Eu tenho o direito de discutir e aumentar as minhas experiências religiosas e/ou espirituais seja o que elas possam significar para os outros.

$\mathrm{Eu}$ tenho o direito de exigir que a inviolabilidade do meu corpo seja respeitada após a morte. Eu tenho o direito de ser assistido por pessoas ca- rinhosas, sensíveis e com capacidade de sentir prazer em me ajudar em face da morte.

FERRAZ, A. F. et alii, The nursing care to patients in the terminal stage.Rev. Bros. Enf., Brasília 39 (1) : 50-60, Jan./Mars. 1986.

\section{REFERÊNCIAS BIBLIOGRÁFICAS}

1. ABR AHIM, J. M. F. \& CARRARO V. Morte. Rev. Gaúcha Enf., Porto Alegre, 5 (1) 1-9. jan. 1984.

2. ASSUMPÇÃO, E. A. Comportar-se fazendo. Belo Horizonte PUC-MG/FUMARC. 1984.

3. Os aspectos culturais e psicológicos da morte. In: ASSUMPÇÃO, E. A. et alii. Morte $e$ Suicídio. Petrópolis, Vozes, 1984. Cap. 1.

4. BELAND, I. \& PASSOS, J. Enfermagem clinica. São Paulo, Editora Pedagógica Universitária, 1978. v. 1 .

5. EPSTEIN, C. Interação efetiva na enfermagem. São Paulo, E. P. U., Editora Universidade de São Paulo, 1977.

6. FUERST, E. W. et alii. Fundamentos de enfermagem. 5 ed. Rio de Janeiro, Interamericana, 1977.

7. GHEZZI, M. J. Assistência de enfermagem ao paciente em fase terminal de câncer. Rev. Gaúcha Enf., Porto Alegre 3 (2): 127-32, jun. 1982.

8. Apud. COSTA, L. A. T. Situaçôes, vida morte. Rio de Janeiro, 1971. UFRS. Escola de Enfermagem Ana Neri.

9. HORTA, W. A. Processo de enfermagem. São Paulo, E. P. U.; Ed. da Universidade de São Paulo, 1979.

10. KUBLER-ROSS, E. Morte estágio final da evolução. Rio de Janeiro, Record, 1975.

11. MONTESANO, M. Assistência ao paciente conceroso em fase terminal: trabalho de psiquiatria. rev. Paul. Enf., São Paulo, 3 (3): 82-3, maio/jun. 1983.

12. PIMENTEL, M. A. et alii. Amenizando a morte. Rev. Enf. Novas Dimens., São Paulo, 4 (6): 3514 , 1978.

13. SILVA, M. J A enfermagem diante do paciente terminal e da morte in: ASSUMPÇÃO, E. A. et ali i. Morte e Suicidio. Petrópolis, Vozes, 1984. p. $142-6$.

14. VEIGA, D. A. a enfermeira e o paciente que vai morrer. Rev. Gaúcha Enf., Porto Alegre, 5 (1): 113-8, jan. 1984

\footnotetext{
*Esta "Declaração de Direitos" foi criada em uma reunião de trabalho sobre "O Paciente Terminal e a Pessoa que o Assiste" ("The Terminally III Patient and the Helping Person") em Lansing, Mich, patrocinada pelo Southwestern Michigan Inservice Education Council, dirigida por Amelia J. Barbus, professora associada de Enfermagem da Wayne State University Detroit.
} 